\title{
Longitudinal Change in the Neural Bases of Adolescent Social Self-Evaluations: Effects of Age and Pubertal Development
}

\author{
Jennifer H. Pfeifer, ${ }^{1}$ Lauren E. Kahn, ${ }^{1}$ Junaid S. Merchant, ${ }^{1}$ Shannon J. Peake, ${ }^{1}$ Kim Veroude, ${ }^{1,2}$ Carrie L. Masten, ${ }^{3}$ \\ Matthew D. Lieberman, ${ }^{4}$ John C. Mazziotta, ${ }^{5}$ and Mirella Dapretto ${ }^{5,6}$ \\ ${ }^{1}$ Department of Psychology, University of Oregon, Eugene, Oregon 97403-1227, 2Department of Educational Neuroscience, Faculty of Psychology and \\ Education, \& LEARN! Institute, VU University Amsterdam, Amsterdam, The Netherlands, ${ }^{3}$ Department of Psychology and Human Development, \\ Vanderbilt University, Nashville, Tennessee 37240-7817, and ${ }^{4}$ Department of Psychology, ${ }^{5}$ Ahmanson-Lovelace Brain Mapping Center, and ${ }^{6}$ UCLA-FPR \\ Center for Culture, Brain, \& Development, University of California, Los Angeles, California 90095
}

Self-evaluations undergo significant transformation during early adolescence, developing in parallel with the heightened complexity of teenagers' social worlds. Intuitive theories of adolescent development, based in part on animal work, suggest that puberty is associated with neural-level changes that facilitate a "social reorientation" (Nelson et al., 2005). However, direct tests of this hypothesis using neuroimaging are limited in humans. This longitudinal fMRI study examined neurodevelopmental trajectories associated with puberty, self-evaluations, and the presumed social reorientation during the transition from childhood to adolescence. Participants $(N=27$, mean age $=10.1$ and 13.1 years at time points one and two, respectively) engaged in trait evaluations of two targets (the self and a familiar fictional other), across two domains of competence (social and academic). Responses in ventromedial PFC increased with both age and pubertal development during self-evaluations in the social domain, but not in the academic domain. These results suggest that changes in social self-evaluations are intimately connected with biology, not just peer contexts, and provide important empirical support for the relationship between neurodevelopment, puberty, and social functioning.

\section{Introduction}

Adolescence is widely regarded as a special time for self-discovery and identity exploration. Research confirms that this is a period of significant self-development, including a growing sense of uniqueness but also connection with others, which is affected by multiple factors, including biology and context (Harter, 1999). For example, pubertal development is thought to fuel a "social reorientation" (Nelson et al., 2005) that heightens the salience of peer relations. As a result, social self-concepts (evaluative selfknowledge pertaining to the peer domain) might be in a state of

Received Aug. 24, 2012; revised Feb. 12, 2013; accepted March 11, 2013.

Author contributions: J.H.P., M.D.L., J.C.M., and M.D. designed research; J.H.P. and C.L.M. performed research; J.H.P., L.E.K., J.S.M., S.J.P., and K.V. analyzed data; J.H.P., L.E.K., J.S.M., S.J.P., K.V., C.L.M., M.D.L., and M.D. wrote the paper.

This work was supported by the National Institutes of Health Grants F31MH075299, L40HD059442, and L40MH087356 to J.H.P.; the Sante Fe Institute Consortium, Brain Mapping Medical Research Organization, Brain Mapping Support Foundation, Pierson-Lovelace Foundation, Ahmanson Foundation, Tamkin Foundation, Jennifer Jones-Simon Foundation, Capital Group Companies Charitable Foundation, Robson Family, William M. and Linda R. Dietel Philanthropic Fund at the Northern Piedmont Community Foundation, and Northstar Fund; and National Center for Research Resources Grants RR12169, RR13642 and RR00865, a component of the National Institutes of Health. Its contents are solely the responsibility of the authors and do not necessarily represent the official views of National Center for Research or National Institutes of Health. The funders had no role in study design, data collection and analysis, decision to publish, or preparation of the manuscript.

The authors declare no competing financial interests.

Correspondence should be addressed to Dr. Jennifer H. Pfeifer, Department of Psychology, 1227 University of Oregon, Eugene, 0R 97401. E-mail: jpfeifer@uoregon.edu.

DOI:10.1523/JNEUROSCI.4074-12.2013

Copyright $\odot 2013$ the authors $\quad 0270-6474 / 13 / 337415-05 \$ 15.00 / 0$ considerable flux and sensitivity. Transitioning from elementary to middle school, meanwhile, is known to significantly impact academic self-concepts (Eccles et al., 1993); they become more negative overall, and academic engagement decreases. Yet we know very little about how changes in brain function relate to adolescent self-development, and in particular we lack information about longitudinal changes in the neural correlates of selfevaluations across social and academic domains.

The current investigation advances the study of selfdevelopment through the use of developmental social neuroscience methods, in contrast to the self-report and theory-based approaches that have dominated past work in this area. Reviews of the neural systems supporting adult self-evaluations have converged on a set of critical regions, predominantly focusing on cortical midline structures: medial prefrontal cortex (mPFC, including rostral anterior cingulate cortex $[\mathrm{ACC}]$ ) and medial posterior parietal cortex (mPPC) (Van Overwalle, 2009; Northoff et al., 2011). To our knowledge, only three studies have examined the neural systems supporting self-evaluations in typically developing samples. Together, they confirm that mPFC (including rostral ACC) is central to self-referential processing in children and adolescents (Pfeifer et al., 2007, 2009; Ray et al., 2009). However, the current study is the first to apply a longitudinal fMRI approach to the study of self-development. This allows us to investigate within-subject neural changes related to age and puberty at the transition point from childhood to adolescence, rather than broad cross-sectional differences among children, 
adolescents, and adults. Furthermore, although there are strong links between puberty and changes in social behaviors (Forbes and Dahl, 2010), much of the evidence connecting pubertal development with neural changes comes from animal models (Romeo, 2003; Sisk and Zehr, 2005; Schulz et al., 2009; Spear, 2011). We hypothesized that the heightened salience of selfdevelopment and peer relations in adolescence would be reflected in longitudinal increases in $\mathrm{mPFC}$ response during self-evaluations, particularly in the social domain as a function of puberty (Nelson et al., 2005).

\section{Materials and Methods}

Twenty-seven neurotypical individuals (18 female) with no history of psychiatric, neurological, or learning disorders were scanned while making evaluations of self and other in the social and academic domains, once at age 10 (mean $\pm S D, 10.1 \pm 0.35$ years) and again at age $13(13.1 \pm 0.33$ years). The other target was a fictional character, Harry Potter, about whom participants all had substantial knowledge (as indicated via questionnaire). An equal number of items were positive and negative valence. Sample phrases included: "I am popular," "I wish I had more friends," "I like to read just for fun," and "Writing is so boring" (see Pfeifer et al., 2007 , for a complete description of paradigm development and full list of stimuli). Three participants were included both in this sample and that of Pfeifer et al. (2007).

As described previously by Pfeifer et al. (2007), one phrase was presented every $3 \mathrm{~s}$, leaving $\sim 2 \mathrm{~s}$ to respond as phrases averaged $1 \mathrm{~s}$ in duration. The 40 phrases were organized into four blocks of 20 stimuli each, and the four task blocks alternated between reporting whether the phrase described oneself or a fictional, highly familiar other: Harry Potter. Before the scan, it was ensured that all participants had sufficient familiarity with Harry Potter based on self-reports of knowledge about him on a 5-point scale (mean, 3.76 and 3.59 for T1 and T2, respectively). Variability in knowledge across time points was not significantly correlated with brain activity extracted from the region of ventral mPFC that demonstrated longitudinal increases during self $>$ other evaluations. Objectively, each participant reported reading at least one book, or watching at least three movies, from the series. Block order was counterbalanced between participants. The initial block was always followed by a block containing the same phrases but applied to the remaining target (self or other), and then the last two blocks contained the remaining phrases (applied to the self and other targets in the same order as the first two blocks). Each of the four blocks was $75 \mathrm{~s}$ long, and included the 20 stimulus trials (ordered pseudorandomly) and five null events during which no phrase was presented. Blocks were separated by $21 \mathrm{~s}$ of rest. Participants were verbally instructed on this task outside the scanner and before the initiation of the run, and then reminded of these instructions at the start of each block during the run.

At both time points, participants also self-reported about observed changes in visible secondary sex characteristics (e.g., pubic hair, skin problems, genital development) using the Pubertal Development Scale (PDS) (Petersen et al., 1988).

The PDS was always administered with a researcher nearby to answer any questions participants had about the meaning of items. Parents were notified several days in advance of the session that a form assessing pubertal development would be part of the assessment, which gave parents the opportunity to talk with their children about this topic in advance if they so desired. We used the scoring guidelines provided by Petersen et al. (1988), and we omitted the social comparison question (about development relative to the pace of peers). There was a highly significant increase from T1 to T2 on the PDS (mean \pm SD: T1, $1.64 \pm 2.58$; T2, $0.46 \pm 0.68$; $\left.t_{(1,26)}=7.95, p \sim 0\right)$. Because there were no significant gender differences in PDS scores at either time point (female, 1.66 and 2.66, male 1.60 and 2.40 , not significant), analyses collapsed across gender to increase statistical power (consistent with the methods of Pfeifer et al., 2011) and further appropriate because there were no significant differences in task performance by gender. At T1, there was no relationship between chronological age and pubertal development $\left(r_{(25)}=0.04\right.$, not significant $)$. At $\mathrm{T} 2$, chronological age and pubertal development were moderately corre- lated in the expected direction, although this was only a trend $\left(r_{(25)}=\right.$ 0.29 , one-tailed $p=0.07$ ). It should be noted that two participants (one girl and one boy) each "regressed" by less than one point on average in their self-reports of pubertal development, but the presence and proportion of "regressions" in this sample are highly consistent with that reported in other longitudinal research using the PDS (e.g., Petersen et al., 1988). Furthermore, excluding these two participants from correlational analyses relating to pubertal development did not change the results. To assess the influence of puberty independently from that of chronological age, linear regression was conducted to obtain unstandardized residual values of pubertal development, indexing variability in PDS scores that could not be explained by age (in other words, age was used to predict PDS at each time point and the unstandardized residuals were saved, then used in further analyses).

fMRI images were acquired on a Siemens Allegra 3T scanner. The functional scan lasted $4 \mathrm{~min} 54 \mathrm{~s}$ (gradient echo, $\mathrm{TR}=3000 \mathrm{~ms}, \mathrm{TE}=25$ $\mathrm{ms}$, flip angle $=90^{\circ}$, matrix size $64 \times 64$, FOV $=20 \mathrm{~cm}$, 36 slices, 3.125 $\mathrm{mm}$ in-plane resolution, $3 \mathrm{~mm}$ thick). For each participant, a highresolution structural T2-weighted echo-planar imaging volume (spinecho, $\mathrm{TR}=5000 \mathrm{~ms}, \mathrm{TE}=33 \mathrm{~ms}$, matrix size $128 \times 128, \mathrm{FOV}=20 \mathrm{~cm}$, 36 slices, $1.56 \mathrm{~mm}$ in-plane resolution, $3 \mathrm{~mm}$ thick) was also acquired coplanar with the functional scan. Stimuli were presented to participants through high-resolution magnet-compatible goggles.

fMRI data were converted from dicoms using MRIconvert (http://lcni. uoregon.edu/ jolinda/MRIConvert/), and then skull-stripped using FSL's Brain Extraction Tool (http://www.fmrib.ox.ac.uk/analysis/research/bet/ bet.pdf). ARTrepair (http://cibsr.stanford.edu/tools/human-brain-project/ artrepair-software.html) was used to detect and fix bad slices in the unpreprocessed functional data. Structural images were then manually reoriented to the AC-PC, after which preprocessing was performed in Neuroelf (http:// neuroelf.net/) using SPM8 functions as follows: (1) structural images for each participant were first coregistered to the SPM T1 template; (2) functional images were then realigned to correct for head motion using a twopass least-squares approach and a six parameter (rigid body) spatial transformation (to the first image, then to the mean image); (3) realigned images were coregistered to their respective high-resolution structural image using a rigid-body transformation in three dimensions; (4) the structural image was segmented based on the SPM template tissue probability maps; (5) the determined parameters from the segmentation were used to spatially normalize functional images into a Talairach-compatible atlas using $12 \mathrm{pa}-$ rameter affine transformation; and (6) finally, all functional images were smoothed using an $6 \mathrm{~mm}$ full-width, half-maximum isotropic Gaussian kernel. In each run, participants demonstrated $<5 \%$ of images with bad slices detected and fixed by ARTrepair, and $<0.5 \mathrm{~mm}$ mean image-to-image motion or $<5 \mathrm{~mm} \max$ (single) image-to-image motion.

After preprocessing, statistical analyses were implemented in SPM8 (Wellcome Department of Cognitive Neurology, London; http://www. fil.ion.ucl.ac.uk/spm/). For each subject, condition effects were estimated according to the general linear model, following the methods by Pfeifer et al. (2007). Blocks (Self Social, Other Social, Self Academic, and Other Academic) were convolved with a canonical hemodynamic response function. Low-frequency drifts were removed by global scaling, and motion parameters were included as regressors of no interest. T1 and T2 were modeled as two separate runs. The resulting contrast images were entered into group-level analyses using random effects models. Paired $t$ tests and a $2 \times 2 \times 2$ ANOVA was conducted with three factors: target (self and other), domain (social and academic), and age (T1 and $\mathrm{T} 2$ ). Unless otherwise noted, results were thresholded at $p<0.001, k=$ 10 voxels $(3 \times 3 \times 3 \mathrm{~mm})$, to balance between types I and II errors; in particular, results surviving FWE correction are indicated as such in the text and table.

\section{Results}

Our first analyses investigated responses during self and other evaluations that were stable over time. The main effect of target (self vs other) revealed robust activations not only in cortical midline structures, but also in ventral striatum (VS) (Fig. 1; Table 1). Responses in mPFC (rostral and dorsal ACC) as well as VS 


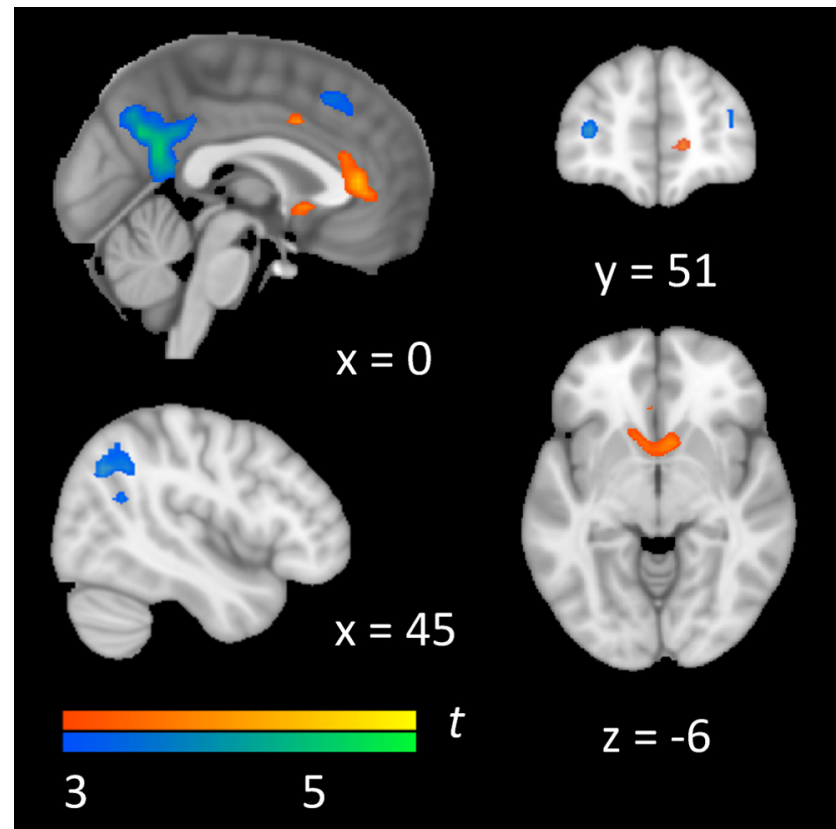

Figure 1. Hot colors represent the self $>$ other contrast, and cool colors represent the other $>$ self contrast. $x, y$, and $z$ refer to the left-right, anterior-posterior, and superiorinferior coordinates in MNI space.

Table 1. Neural responses to self and other evaluations (main effect of target) across time points $^{a}$

\begin{tabular}{|c|c|c|c|c|c|c|c|}
\hline Region & BA & & $x$ & $y$ & $Z$ & $t$ & $k$ \\
\hline \multicolumn{8}{|l|}{ Self $>0$ ther } \\
\hline $\mathrm{mPFC}(\mathrm{rACC})$ & $24 / 32$ & $b$ & -3 & 36 & 6 & 5.48 & 259 \\
\hline Ventral striatum & & $b$ & 6 & 15 & -3 & 4.32 & 259 \\
\hline $\mathrm{dACC}$ & 24 & & 3 & 9 & 36 & 4.68 & 18 \\
\hline \multicolumn{8}{|l|}{ 0ther $>$ Self } \\
\hline $\mathrm{mPPC}$ & 23/26/29/31 & $b$ & 9 & -51 & 15 & 5.61 & 368 \\
\hline $\mathrm{dmPFC}$ & 8 & & 3 & 24 & 48 & 4.26 & 49 \\
\hline dIPFC & $6 / 8$ & & -39 & 12 & 45 & 4.07 & 51 \\
\hline rIPFC & $10 / 46$ & & 33 & 51 & 9 & 3.73 & 16 \\
\hline TPJ & 39 & & 45 & -63 & 36 & 3.66 & 42 \\
\hline
\end{tabular}

${ }^{a}$ Results were thresholded at $p<0.001$, uncorrected for magnitude; and $k=10$ voxels $(3 \times 3 \times 3 \mathrm{~mm})$.

${ }^{b}$ Clusters that survived FWE correction.

$B A$, Brodmann's area; $x$, left-right; $y$, anterior-posterior; $z$, inferior-superior; $t, t$ score at those coordinates (local maxima or submaxima); $k$, the number of voxels in the cluster; $\mathrm{PFC}$, prefrontal cortex; $\mathrm{ACC}$, anterior cingulate cortex; $\mathrm{PCC}$, posterior cingulate cortex; TPJ, temporoparietal junction; m, medial; r, rostral; d, dorsal; l, lateral.

were greater during self-evaluations, whereas responses in $\mathrm{mPPC}$, lateral PFC, and temporoparietal junction were greater during other-evaluations.

We conducted an additional pair of conjunction analyses to explore the main effect of target. As implemented in SPM8 and following the recommendations of Nichols et al. (2005), we used the "logical and" strategy, which requires that the results of all contrasts entered into the conjunction analysis survive the minimum test statistic. Two conjunction analyses were run. One looked for conjunctions of self $>$ other effects at both time points, whereas the other looked for conjunctions of other $>$ self effects at both time points. Initially, only one cluster survived: for other $>$ self, common activation across time points was observed in the $\operatorname{mPPC}(9,-51,15, t=3.95, k=138)$. When the minimum test statistic was relaxed to $p<0.005$ (from $p<0.001$, which may be advisable as the "logical and" conjunction analysis is conservative; Nichols et al., 2005), whereas the extent threshold was maintained (at $k=10$ ), two additional clusters survived: for
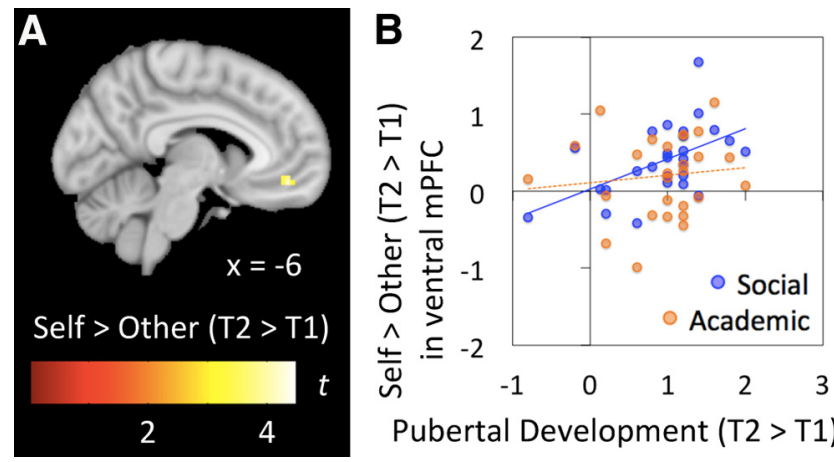

Figure 2. $\quad \mathrm{T} 1$ and $\mathrm{T} 2$ refer to age 10 and 13 , respectively. $x$ indicates the left-right coordinate in MNI space. $\boldsymbol{A}$, Responses that increase from T1 to T2 during evaluations of self $>$ other. $\boldsymbol{B}$, Mean parameter estimates of activity are extracted from the ventral $\mathrm{mPFC}$ cluster shown in $\boldsymbol{A}$.

self $>$ other, common activations across time points were observed in the $\operatorname{mPFC}(-6,36,6, t=3.04, k=10)$ and VS $(3,12$, $-3, t=3.01, k=12)$. This confirmed that the three clusters reported in Table 1 to survive FWE correction (mPFC and VS for self $>$ other, $\mathrm{mPPC}$ for other $>$ self) were indeed responsive at both time points.

Our primary inquiries, however, focused on change over time. As hypothesized, responses in a ventral aspect of $\operatorname{mPFC}(-9,45$, $-12, t=4.5, k=14)$ increased from age 10 to age 13 , more for evaluations of self than other (Fig. $2 A$ ). Indeed, this was the only region across the whole brain to demonstrate longitudinal increases. No regions exhibited significant decreases from age 10 to age 13 when collapsing across domains (although in the social domain only, there was a significant longitudinal decrease in hippocampal activity $[-27-18-9, t=4.5, k=16]$ during the self $>$ other contrast).

Post hoc ROI analyses were performed by extracting parameter estimates of blood-oxygenation level-dependent signal change in this ventral mPFC cluster exhibiting longitudinal change (averaging across all voxels), from each condition relative to baseline, at each time point (following the methods of Pfeifer et al., 2011). These analyses demonstrated that the increase in ventral mPFC response was significant in the social domain $(p=0.0001)$ but marginal in the academic domain $(p=0.0556)$.

Furthermore, as predicted, pubertal development (PDS scores at age 13, controlling for PDS scores at age 10, each of which was residualized for age within time point) was significantly positively correlated with increased responses in this ventral mPFC ROI during evaluations of self versus other in the social domain $\left(r_{(25)}=0.53, p<0.005\right)$, but not in the academic domain $\left(r_{(25)}=\right.$ 0.11 , not significant; Fig. $2 B$ ), and these two correlations were significantly different $(z=2.25, p=0.025)$. Additionally, correlations between pubertal development and responses in this ventral mPFC ROI during evaluations of self versus other in the social domain were consistent across gender $\left(r_{(16)}=0.45\right.$ for girls, $r_{(7)}=0.74$ for boys; $p=0.06$ and 0.02 , respectively). Results were also the same whether correlations between ventromedial PFC activity were conducted using raw or residualized PDS scores, perhaps because of the borderline moderate correlation between PDS and age at T2 only. Such a pattern is to be expected within a tight age range, although with a much larger age range, the PDS would be more strongly correlated with age. Finally, supplementary whole-brain analyses indicated that pubertal development was not significantly positively or negatively correlated with longitudinal changes in any other brain regions when collapsing across domains. 


\section{Discussion}

This longitudinal fMRI study allowed a robust characterization of neural responses during evaluations of self versus other in late childhood and early adolescence. Evaluations of another social target engaged $\mathrm{mPPC}$, lateral PFC, and temporoparietal junction, a region implicated in mentalizing and attention (Scholz et al., 2009). This suggests that executive functions, memory, and perspective taking are implicated in other evaluations. Meanwhile, self-evaluations commonly engaged $\mathrm{MPFC}$ and VS, a region implicated in reward processing (Cooper and Knutson, 2008), including rewards tied to self-specific processing and selfdisclosure (Lieberman et al., 2004; Northoff and Hayes, 2011; Tamir and Mitchell, 2012). Together with the robust body of work demonstrating anatomical and functional linkages between VS and ventral mPFC, this suggests that self-evaluative processing may inherently involve the "generation of affective meaning" (Roy et al., 2012, p. 147).

The degree to which ventral $\mathrm{mPFC}$ responded more during self-evaluations than other-evaluations increased from age 10 to 13 , particularly in the social domain. Ventral mPFC is not only associated with self-referential processing (Van Overwalle, 2009; Northoff et al., 2011), but also with reward and valuation processes (Rangel et al., 2008; Chib et al., 2009; Hare et al., 2009). As such, this neurodevelopmental pattern is consistent with the heightened importance adolescents place on peer relationships and sociometric status (for review, see Pfeifer and Peake, 2011). It also extends prior neuroimaging work conducted with a largely nonoverlapping sample comparing 10-year-olds with young adults, which found that a more dorsal region of $\mathrm{mPFC}$ was more responsive in children during self-evaluations than adults. Thus, whereas dorsal mPFC may be more engaged in late childhood during self-evaluations, ventral mPFC may be increasingly recruited in early adolescence. Future studies should endeavor to track responses in both these regions during self-evaluations (relative to evaluations of others) to determine when recruitment of each region peaks.

Furthermore, this same region of ventral mPFC differentiates between self and others in neurotypical adults but fails to do so in adults and adolescents with autism spectrum disorders (Lombardo et al., 2010; Pfeifer et al., 2013). In typically developing children and adolescents, the degree to which ventral mPFC responds more to self than other is significantly positively correlated with social responsiveness (Pfeifer et al., 2013). Together, these findings suggest that this differential response in ventral $\mathrm{mPFC}$ during self-evaluative processing makes important contributions to successful social cognition.

Finally, the discovery that level of pubertal development (independent of age) was significantly associated with increased selfother differentiation in ventral mPFC for the social but not academic domain is an important contribution to the existing literature. Existing animal work demonstrates that puberty affects neurodevelopment of structures and transmitters strongly implicated in social behavior (Romeo, 2003; Sisk and Zehr, 2005; Ahmed et al., 2008; Schulz et al., 2009), but studies directly testing the theorized associations between neural, pubertal, and social changes in adolescent humans are still few in number. Prior studies also linked pubertal development either with structural metrics (Bramen et al., 2011; Peper et al., 2011), or with responses elicited by socioemotional or rewarding stimuli (Forbes et al., 2010, 2011; Op de Macks et al., 2011; Moore et al., 2012). To our knowledge, however, only one study has contrasted patterns of brain function between conditions that were relatively more and less socially relevant (Goddings et al., 2012). In this study, levels of sex steroid hormones positively correlated with responses in left temporal pole during social emotion processing (embarrassment and guilt, compared with basic emotion processing of fear and disgust). Meanwhile, age (controlling for pubertal development) negatively correlated with activity in dorsal (but not ventral) $\mathrm{mPFC}$, making the findings complementary. In the present study, assessing evaluative processing in an academic domain (Hymel et al., 1999; Denissen et al., 2007), which is comparatively much less social and more objective by definition, likewise allowed us to conduct an empirical test that provided strong support at the neural level for the "social reorientation" teenagers are proposed to experience (Nelson et al., 2005). More generally, our findings illustrate the tight coupling between biological and social changes during puberty that may facilitate refinement of a unique, multifaceted, and relational self during adolescence. In other words, while academic self-evaluations may change because of contextual factors, such as school transitions (Eccles et al., 1993), social self-evaluative change is intimately connected with biology and not just interpersonal contexts.

\section{Notes}

Supplemental material for this article is available at http://dsn.uoregon. edu/Publications_files/SuppFig1.pdf. The figure depicts paired scores on the Pubertal Development Scale across time points. This material has not been peer reviewed.

\section{References}

Ahmed EI, Zehr JL, Schulz KM, Lorenz BH, DonCarlos LL, Sisk CL (2008) Pubertal hormones modulate the addition of new cells to sexually dimorphic brain regions. Nat Neurosci 11:995-997. CrossRef Medline

Bramen JE, Hranilovich JA, Dahl RE, Forbes EE, Chen J, Toga AW, Dinov ID, Worthman CM, Sowell ER (2011) Puberty influences medial temporal lobe and cortical gray matter maturation differently in boys than girls matched for sexual maturity. Cereb Cortex 21:636-646. CrossRef Medline

Chib VS, Rangel A, Shimojo S, O’Doherty JP (2009) Evidence for a common representation of decision values for dissimilar goods in human ventromedial prefrontal cortex. J Neurosci 29:12315-12320. CrossRef Medline

Cooper JC, Knutson B (2008) Valence and salience contribute to nucleus accumbens activation. Neuroimage 39:538-547. CrossRef Medline

Denissen JJ, Zarrett NR, Eccles JS (2007) I like to do it, I'm able, and I know I am: longitudinal couplings between domain-specific achievement, selfconcept, and interest. Child Dev 78:430-447. CrossRef Medline

Eccles JS, Midgley C, Wigfield A, Buchanan CM (1993) Development during adolescence: the impact of stage-environment fit on young adolescents' experiences in schools and in families. Am Psychol 48:90-101. CrossRef Medline

Forbes EE, Dahl RE (2010) Pubertal development and behavior: hormonal activation of social and motivational tendencies. Brain Cogn 72:66-72. CrossRef Medline

Forbes EE, Phillips ML, Silk JS, Ryan ND, Dahl RE (2011) Neural systems of threat processing in adolescents: role of pubertal maturation and relation to measures of negative affect. Dev Neuropsychol 36:429-452. CrossRef Medline

Forbes EE, Ryan ND, Phillips ML, Manuck SB, Worthman CM, Moyles DL, Tarr JA, Sciarrillo SR, Dahl RE (2010) Healthy adolescents' neural response to reward: associations with puberty, positive affect, and depressive symptoms. J Am Acad Child Adolesc Psychiatry 49:162-172.e1-e5. CrossRef Medline

Goddings AL, Burnett Heyes S, Bird G, Viner RM, Blakemore SJ (2012). The relationship between puberty and social emotion processing. Dev Sci 15: 801-811. CrossRef Medline

Hare TA, Camerer CF, Rangel A (2009) Self-control in decision-making involves modulation of the vmPFC valuation system. Science 324:646648. CrossRef Medline

Harter S (1999) The construction of the self: a developmental perspective. New York: Guilford.

Hymel S, LeMare L, Ditner E, Woody EZ (1999) Assessing self-concept in 
children: variations across self-concept domains. Merrill-Palmer Q 45:602-623.

Lieberman MD, Jarcho JM, Satpute AB (2004) Evidence-based and intuition-based self-knowledge: an fMRI study. J Pers Soc Psychol 87: 421-435. CrossRef Medline

Lombardo MV, Chakrabarti B, Bullmore ET, Sadek SA, Pasco G, Wheelwright SJ, Suckling J, Baron-Cohen S (2010) Atypical neural selfrepresentation in autism. Brain 133:611-624. CrossRef Medline

Moore WE 3rd, Pfeifer JH, Masten CL, Mazziotta JC, Iacoboni M, Dapretto M (2012) Facing puberty: associations between pubertal development and neural responses to affective facial displays. Soc Cogn Affect Neurosci 7:35-43. CrossRef Medline

Nelson EE, Leibenluft E, McClure EB, Pine DS (2005) The social reorientation of adolescence: a neuroscience perspective on the process and its relation to psychopathology. Psychol Med 35:163-174. CrossRef Medline

Nichols T, Brett M, Andersson J, Wager T, Poline JB (2005) Valid conjunction inference with the minimum statistic. Neuroimage 25:653-660. CrossRef Medline

Northoff G, Hayes DJ (2011) Is our self nothing but reward? Biol Psychiatry 69:1019-1025. CrossRef Medline

Northoff G, Qin P, Feinberg TE (2011) Brain imaging of the self: conceptual, anatomical and methodological issues. Consciousness Cogn 20:5263. CrossRef Medline

Op de Macks ZA, Gunther Moor B, Overgaauw S, Güroðlu B, Dahl RE, Crone EA (2011) Testosterone levels correspond with increased ventral striatum activation in response to monetary rewards in adolescents. Dev Cogn Neurosci 1:506-516. CrossRef Medline

Peper JS, Hulshoff Pol HE, Crone EA, Van Honk J (2011) Sex steroids and brain structure in pubertal boys and girls: a mini-review of neuroimaging studies. Neuroscience 191:28-37. CrossRef Medline

Petersen AC, Crockett L, Richards M, Boxer AA (1988) Self-report measure of pubertal status: reliability, validity, and initial norms. J Youth Adolesc 17:117-133. CrossRef

Pfeifer JH, Peake SJ (2012) Self-development: integrating cognitive, socioemotional, and neuroimaging perspectives. Dev Cogn Neurosci 2:55-69. CrossRef Medline

Pfeifer JH, Lieberman MD, Dapretto M (2007) I know you are but what am I: neural bases of self-and social knowledge retrieval in children and adults. J Cogn Neurosci 19:1323-1337. CrossRef Medline
Pfeifer JH, Masten CL, Borofsky LA, Dapretto M, Fuligni AJ, Lieberman MD (2009) Neural correlates of direct and reflected self-appraisals in adolescents and adults: when social perspective-taking informs self-perception. Child Dev 80:1016-1038. CrossRef Medline

Pfeifer JH, Masten CL, Moore WE 3rd, Oswald TM, Iacoboni M, Mazziotta JC, Dapretto M (2011) Entering adolescence: resistance to peer influence, risky behavior, and neural changes in emotion reactivity. Neuron 69:1029-1036. CrossRef Medline

Pfeifer JH, Merchant JS, Colich NL, Hernandez LM, Rudie JD, Dapretto M (2013) Neural and behavioral responses during self-evaluative processes differ in youth with and without autism. J Autism Dev Disord 43:272-285. CrossRef Medline

Rangel A, Camerer C, Montague PR (2008) A framework for studying the neurobiology of value-based decision making. Nat Rev Neurosci 9:545556. CrossRef Medline

Ray RD, Shelton AL, Hollon NG, Michel BD, Frankel CB, Gross JJ, Gabrieli JD (2009) Cognitive and neural development of individuated selfrepresentation in children. Child Dev 80:1232-1242. CrossRef Medline

Romeo RD (2003) Puberty: a period of both organizational and activational effects of steroid hormones on neurobehavioral development. J Neuroendocrinol 15:1185-1192. CrossRef Medline

Roy M, Shohamy D, Wager TD (2012) Ventromedial prefrontal-subcortical systems and the generation of affective meaning. Trends Cogn Sci 16:147156. CrossRef Medline

Scholz J, Triantafyllou C, Whitfield-Gabrieli S, Brown EN, Saxe R (2009) Distinct regions of right temporo-parietal junction are selective for theory of mind and exogenous attention. PLoS One 4:e4869. CrossRef Medline

Schulz KM, Molenda-Figueira HA, Sisk CL (2009) Back to the future: the organizational-activational hypothesis adapted to puberty and adolescence. Horm Behav 55:597-604. CrossRef Medline

Sisk CL, Zehr JL (2005) Pubertal hormones organize the adolescent brain and behavior. Front Neuroendocrinol 26:163-174. CrossRef Medline

Spear LP (2011) Rewards, aversions and affect in adolescence: emerging convergences across laboratory animal and human data. Dev Cogn Neurosci 1:392-400. CrossRef Medline

Tamir DI, Mitchell JP (2012) Disclosing information about the self is intrinsically rewarding. Proc Natl Acad Sci U S A 109:8038-8043. CrossRef Medline

Van Overwalle F (2009) Social cognition and the brain: a meta-analysis. Hum Brain Mapp 30:829-858. CrossRef Medline 